INTERNATIONAL JOURNAL OF
ORGANIZATIONAL LEADERSHIP
ORAGANIZATIONAL
ILAERSHIP

\title{
Personality Matters: Prediction of Organizational Commitment Using Leadership and Personality
}

\author{
Thomas Meixner $^{*}$, Richard Pospisil ${ }^{2}$ \\ ${ }^{1}$ Faculty of Management and Economics, Mendel University, Czech Republic \\ ${ }^{2}$ Faculty of Arts, Palacky University in Olomouc, Czech Republic
}

\begin{abstract}
Keywords:

Organizational commitment;

Employee commitment;

Leadership communication,

Transformational leadership

\section{Received}

03 June 2021

Received in revised form

09 July 2021

Accepted

11 July 2021

*Correspondence:

thomas.meixner@me.com

This study examines the association between employees' personality, organizational commitment, and perception of their leaders' behavior and communication quality. Following this leading research scope, a literature review is conducted, describing different models of organizational commitment and its multi-factorial structure. Leadership is discussed within the framework of transformational, transactional, and avoidant leadership. Leadership and personality variables alike are considered potential predictors of organizational commitment, as it is assessed within this study both from the perspective of emotional and behavioral aspects. The empirical research followed a quantitative, correlative approach, utilizing a sample of $n=300$ German business professionals from various fields and applying measures of emotional and behavioral commitment, perceived leadership communication quality, perceived leadership style (transformational, transactional, or avoidant), and employee personality were administered using an online survey. The statistical analyses followed a correlational approach to explain the interplay between the aspects of leadership, personality, and organizational commitment. Using multiple stepwise regression analyses, the study was able to show how both emotional and behavioral commitment are predicted by employee personality (conscientiousness for both measures, neuroticism additionally for emotional commitment), by the perception of a transformational leadership style, and by perceived leadership communication quality. Using these variables, a total of around $30 \%$ of the overall variance in both measures of organizational commitment could be explained. Thus, the critical function of leadership and leadership communication in organizational commitment may be demonstrated in conjunction with the role of employee personality. Additionally, the measure of emotional and behavioral commitment's criterion validity may be validated.
\end{abstract}




\section{Why Employees Matter}

In a society and economic environment increasingly being dominated by technological advancements and developments that at first glance seem to minimize the need of employees, their relevance still seems to grow, according to experts such as Morgan (2017) or Suseno and Pinnington (2017). At the same time, technologies such as Business Intelligence or Artificial Intelligence (Larson \& Chang, 2016) or robotics (Taylor et al., 2016) and other forms of automatization (Geyer-Klingeberg et al., 2018) make it seem like the business world is taken over by spiritual machines, as Ray Kurzweil (2000) already predicted two decades ago. One of his predictions was that machines would replace a wide variety of work. This would apply to mechanical, menial jobs that can be outsourced to machines and intellectually challenging jobs. According to his predictions, spiritual machines, as the author named those systems that should already have self-awareness and artificial intelligence, also took over so-called white-collar jobs. However, whether this became true or will become true stays unknown and is outside of the scope of this work. However, the rise of such systems did strongly influence the employment market: Machines and technical solutions destroyed jobs, as public perception often labels this development (Balsmeier \& Woerter, 2019). However, the consequences of the ongoing digitalization and subsequent digital transformation (Pretsch, 2019) are also described to be jobcreators and value-creators. Individuals who can perform in a highly complex environment and who can innovate and transform companies and businesses are in higher demand than ever before - a development labelled already two decades ago as a war for talent (Chambers et al., 1998). Winning this war for talent implies from a corporate perspective two important battlefronts: recruiting and retaining talents, thus, highly skilled individuals capable of outperforming the competition (Ulrich, 2015; Ulrich \& Smallwood, 2012).

The present work focuses on the retainment of employees, thus on ways to foster their motivation, reduce their intention to quit (Firth et al., 2004), and strengthen their organizational commitment (Meyer \& Allen, 1991; Meixner, 2020). Organizational commitment describes employees' commitment regarding their company and can be discussed from different viewpoints and perspectives, as this paper will show. One of the core questions of modern leadership and human resource management (HRM) is how this organizational commitment can be fostered - leadership approaches like transformational leadership aim at fostering commitment and at motivating employees, thus actively contributing to a successful pathway through the aforementioned war for talent (Avolio et al., 2004; Busse, 2014a).

\section{Research Gap and Research Question}

As discussed above, organizational commitment can play a major role in a company's success - retaining valuable employees seems to focus contemporary business leaders in a competitive business environment on the product market and the employer market. Different factors influence this commitment, which is a multi-factorial construct (Meixner, 2020). As multifactorial and broad as the construct itself, the predictors and influencers of commitment are shown to be in the scientific literature (Steers, 1977, Yahaya \& Ebrahim, 2016).

Comparatively, little is known about the interplay of employee personality, employee perception of leadership, leadership communication, and how this cluster of aspects influences employee commitment. Especially empirical and quantitative studies on this complex topic seem to be lacking. Various papers have addressed the separate aspects of the general scope of 
this work; the overall relationship of those three clusters (i.e., commitment, perceived leadership, and leadership communication behavior, employee personality) has so far not been addressed in a comparable way. Therein lies the principal research gap to be addressed by the present study: It remains unclear in the current state of research how leadership variables and personality variables work together to predict organizational commitment. Within this study, the researchers aim to include both these internal (personality-related) and external (leadershiprelated) variables to predict organizational commitment utilizing a newly developed measure (Meixner, 2020)

Based on a study by Meixner (2020), the present work seeks to address how emotional commitment and behavioral commitment are linked to employee personality and employee perception of their leaders. The assumption is that both the personality and the perception should play a role in predicting both types of commitment. However, it is further assumed that employee personality and employee perception of their leaders are also connected. Given these assumed relationships within the set of (potential) predictors, a multiple regression analysis will be used, as this approach can also consider the correlations within the set of predictors. Such a robust analytical tool that allows for the assessment of multivariate relationships aims to offer a strong contribution to the pre-existing work on organizational commitment. The empirical study is accompanied by a literature review, covering the state of research regarding the concepts relevant to this paper.

The present paper aims to contribute to the existing literature on organizational commitment, which is a variable of increasing relevance, as Athar (2020) explains with regard to the challenges arising from the Covid-19 crisis. This is also argued by Berberoglu (2018) in regard to organizational performance, where commitment also acts as a predictor. Furthermore, as it becomes increasingly crucial for companies to foster the organizational commitment of their employees, a fostered understanding of potential predictors and their interplay seems crucial. Therefore, it is proposed that the present work not only supports future research on the topic but also clarifies for practitioners how their employees' commitment can be fostered.

\section{Organizational Commitment - A Multi-factorial Construct}

Organizational commitment is a concept of great relevance to practitioners and researchers alike. It is considered a strong predictor of businesses' various financial and organizational outcomes in the contemporary business environment (Cohen, 2017; Yousef, 2017). Typically, organizational or employee commitment is discussed as a multi-factorial construct consisting of multiple layers. Wolf (2014), for example, discussed it as a four-factorial construct consisting of a rational, behavioral, normative, and emotional layer. Allen and Meyer (1990), in their influential research article on organizational commitment, differentiate between three distinctive types of commitment - affective, normative, and behavioral commitment. Affective commitment therein describes the emotional aspect of commitment and thus the strongly relationship-based aspects of commitment. This can be seen in relationship to the emotional layer as described by Wolf (2014). Allen and Meyer $(1990,1991)$ argue that normative behavior describes an individual's notion about whether it is right to stay with a company, independent of the actual relationship. Individuals scoring high in this dimension tend to hold strong beliefs about loyalty towards their company. This is also discussed by Meixner (2020), who argues that this aspect of commitment, thus, should be less influenced by leadership behavior or other 
aspects of the relationship between company and employee and rather be dependent on the individual's personality. Behavioral commitment, lastly, refers to the actual behavior and can be viewed as the opposite of the intention to quit (Elangovan, 2001; Klassen \& Chiu, 2011).

In an empirical evaluation of existing measures on organizational commitment, Meixner (2020) found evidence only for two of the three/four dimensions of organizational commitment - a confirmatory factor analysis based on items derived from a wide variety of measures on organizational commitment only revealed evidence for emotional and behavioral commitment. The remaining two factors lay outside the relationship between employee and employer and are thus, not adequately covered by existing measures. Figure 1 showcases the assumed relationships.

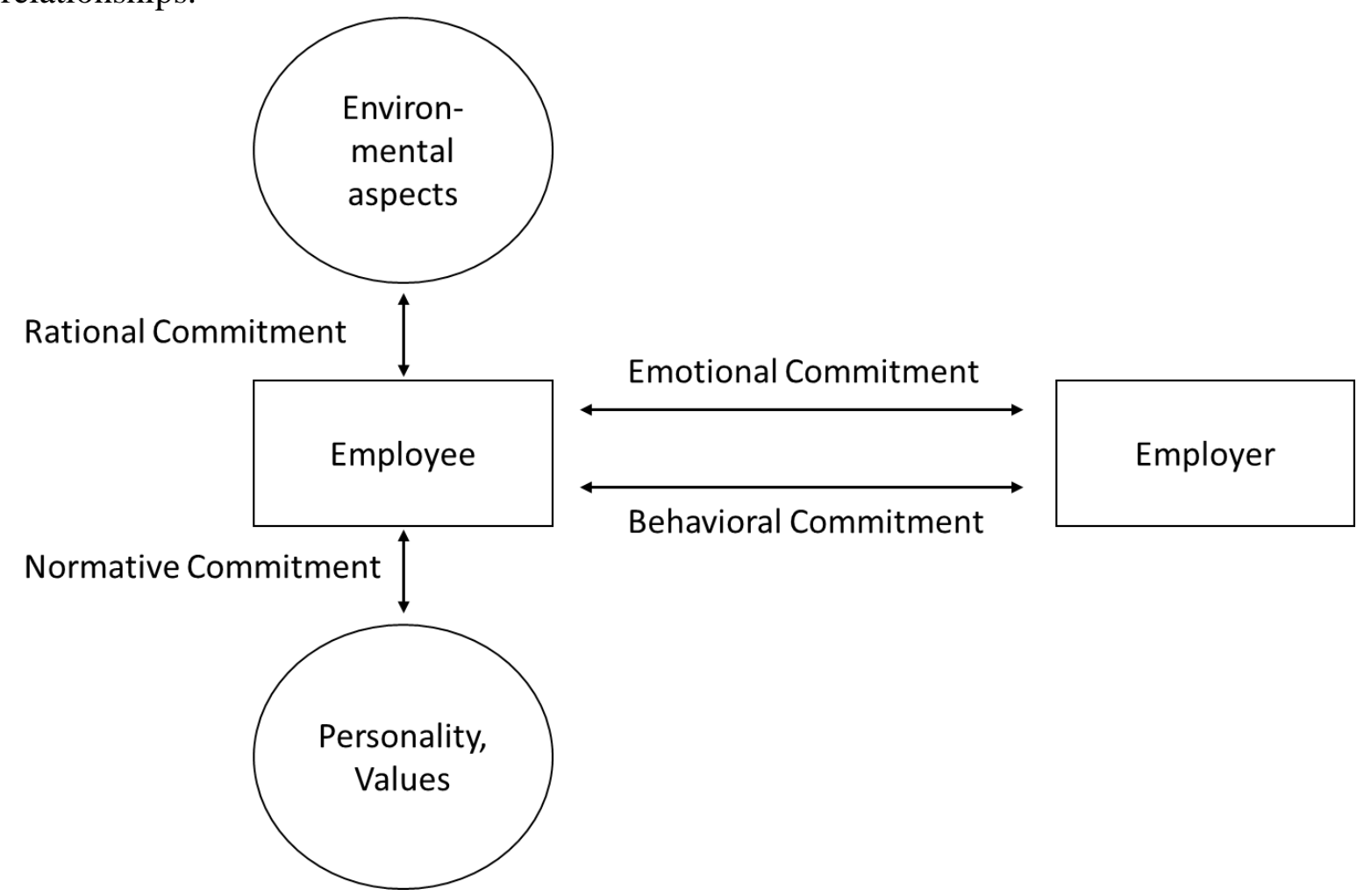

Figure 1. Model of organizational commitment (Meixner, 2020, p 89)

Normative commitment, in alignment with relevant literature, depends on individual's personality and values (Meixner, 2020). As Allen and Meyer (1990) explain, normative commitment is mostly connected to a person's beliefs about whether loyalty to a company is the right thing to do or to feel. Meixner (2020) further argues that rational commitment depends on the relationship between leader and employee. Allen and Meyer (1990) and Wolf (2014) stated that rational commitment also depends less on the leadership behavior or subsequent relationship between leader and employee because of rational aspects like a lack of alternatives or satisfaction with the payment and overall job security.

The present study builds on these findings and addresses organizational commitment as a two-factorial model when viewed in terms of the relationship between employee and leader. Emotional and behavioral commitment thus will be discussed and analyzed within this research paper. 


\section{Leadership and Commitment}

While both scientific literature and managerial practice proposes a wide variety of different leadership approaches and leadership styles (Adams, 2007; Busse, 2014a; Jogulu, 2010), the focus of this paper lies on the distinction between transformational and transactional leadership (Bass \& Avolio, 1994; Bass \& Riggio, 2006). Transformational and transactional leadership approaches, while often portrayed to be two ends of one spectrum, are two separate and distinct approaches towards leadership that can - in theory - appear independent of each other. Thus, a leader can be both transformational and transactional or only either transformational or transactional. This is further accentuated by Neubauer, Bergner, and Felfe (2012), who point out that effective leadership does not follow one single approach, independent of the situation, but is rather situationally aware and reacts to the circumstances in regards to its style. However, leaders typically still do possess a preferred leadership style. Therefore, transactional and transformational leadership are among the most discussed leadership styles, aiming to improve employee motivation and commitment with different tactics.

Transactional leadership, in general, accentuates the transactional nature of leadership (Avolio, Bass, \& Jung, 1999). Employees are given a reward in exchange for their commitment or performance. This transaction of services for rewards, of course, forms the very basis of all employment scenarios. Still, transactional leadership accentuates the transaction above and beyond the regular payment models: Rewards are exchanged for better performance, as is often the case on bonus-based systems as typically found in sales or management roles (Bass, 1997; MacKenzie, Podsakoff, \& Rich, 2001). Such approaches "aim to monitor and control employees through rational or economic means" (Bono \& Judge, 2004, p. 902). The two dimensions of transactional leadership (Avolio, Bass \& Jung, 1999) are contingent reward, where "leaders provide tangible or intangible support and resources to followers in exchange for their efforts and performance" (Bono \& Judge, 2004, p. 902) and management by exception (active), which focuses on "setting standards and monitoring deviations from these standard" (p. 902). The comparative approach of management by exception (passive) only intervenes when necessary, as problems become necessary to manage.

Transformational leadership, again following the distinction presented by Bono and Judge (2004) in regards to its sub-dimensions, focuses in its leadership approach more strongly on the relationship between leader and employee and less on the transactional nature. Leaders following such an approach are characterized by what Bono and Judge (2004) label an idealized influence with "high standards of moral and ethical conduct" (p. 901), thus creating loyalty by leading by positive example. Transformational leaders also typically follow an approach described as inspirational motivation. One of the core goals of transformational leaders, thus, is to inspire employees and motivate them by making them believe in the company's goals and pushing them towards actively wanting to contribute to the success. This stands in stark contrast to the description of transactional leadership, where employees are expected to perform because of their desire for rewards or to avoid punishment. Transformational leadership, rather, focuses on employees' intrinsic motivations and tries to align those with the goals of the company (Bass, 1999). In terms of intellectual stimulation, transformational leaders also "challenge organizational norms, encourage divergent thinking, and who push followers to develop innovative strategies" (Bono \& Judge, 2004, p. 901) and also focus on the individual growth of employees (individual consideration). 
The distinction described here clarifies that the impact of these leadership styles on commitment also seems to be a different one. Meixner (2020) proposed that different types of organizational commitment should be dependent on different predictor variables, implying that especially rational commitment - as defined within the framework of Meyer and Allen (1991) - should be dependent rather on outside variables such as the economic situation or the employment market. Also, it can be deduced that rational commitment should be closely linked to a transactional leadership approach, which focuses on the rational nature of collaborations money in exchange for work (Mahmoud, 2008). Transformational leadership, however, focuses mostly on the emotional and motivational aspects of the relationship between leaders and employees; thus, it also strongly influences these aspects of organizational commitment (Meixner, 2020).

Concludingly, it can be stated that leadership - whether viewed through the lenses of transformational or transactional leadership or through other models - does influence employee commitment, and it also helps create and shape a corporate culture that can also either foster or hinder the development of commitment (Busse, 2014b; Jackson, Meyer, \& Wang, 2013). Concerning hindering organizational commitment, negative leadership styles have to be discussed as they do appear within organizational settings. Schilling (2009) explains that while research typically focused on positive leadership approaches such as the above-mentioned ones, leadership practice also knows a wide set of failures and negative approaches to the topic with devastating consequences for organizations and employees alike. Positive approaches can foster commitment; negative consequences - either stemming from a lack of competence or negative intentions (Schilling, 2009; Schilling \& Schyns, 2014) - can hinder it. One such approach that is typically mentioned within the research landscape is passive avoidant leadership, as it is described to be a counter-perspective to transformational and transactional leadership (Frooman, Mendelson, \& Murphy, 2012; Horwitz et al., 2008) and "is defined as avoiding making decisions at all or reacting only after problems have become serious." (Hetland, Sandal, \& Johnsen, 2008, p. 322). For the sake of the present study, passive-avoidant leadership has therefore been chosen as a counterpart towards transformational and transactional leadership first, as it stands as such a counterpart within the scientific literature, and second, as it seems less evidently and purposefully harmful as other negative leadership approaches. Such openly harmful leadership approaches can be shaped by strong degrees of Machiavellism (Bedell, Hunter, Angie, \& Vert, 2006) or Psychopathy (Mathieu, Neumann, Hare, \& Babiak, 2014) and have accordingly negative effects not only on employees' commitment but also their mental well-being (Mathieu et al., 2014; Landay, Harms, \& Crede, 2019).

\section{A Psychological Construct of Big Five Personality and its Economic Consequences}

An employee's personality is considered one of the vital predictors of his (organizational) behavior (Erdheim, Wang, \& Zickar, 2006; Roberts, 2006; Weiss \& Adler, 1984). Personality also influences commitment towards an organization or a job (Morrison, 1997). Economic research on personality and its influence on various outcomes, such as organizational behavior, sometimes lacks a clear definition of what personality constitutes. In the present study, however, personality is defined by the concept of Big Five, which is prevalent within social sciences, especially psychology, and is described as an excellent predictor of various personal outcomes and behaviors (Goldberg, 1990; Hurtz \& Donovan, 2000). The Big Five model, also known as 
the OCEAN model, consists of five distinct personality factors that are supposed to describe the personality, thus the non-cognitive, stable traits of individuals. The five factors are openness to experience, conscientiousness, extraversion, agreeableness, and neuroticism (Barrick \& Mount, 1991). These five dimensions are described to be mostly stable over the course of a lifetime. However, some empirical studies can observe minor changes within the aging process (CobbClark \& Schurer, 2012). Conscientiousness is among the most intensely studied variables in organizational and personal performance outcomes and is generally described as the strongest predictor of academic and vocational success (Poropat, 2009; Roberts et al., 2009).

Big Five factors can predict major life choices and motivational aspects as well as future behaviors. Among the behaviors predicted by (some factors of) the Big Five of personality are academic access (Poropat, 2009), career success (Judge et al., 1999), and the aforementioned construct of organizational commitment (Erdheim et al., 2006). Erdheim et al. (2006) argued that all five personality dimensions are correlated to the three aspects of organizational commitment as proposed by Allen and Meyer (1991): "Results indicated that Extraversion was significantly related to affective commitment, continuance commitment, and normative commitment. Neuroticism, Conscientiousness, and Openness to Experience were all significantly related to continuance commitment. Lastly, Agreeableness was significantly related to normative commitment" (p. 959).

\section{Methodology \\ Measures}

The present study utilized a combination of various existing measures:

Emotional and Behavioral Commitment. The scales for emotional (20 items) and behavioral (16 items) commitment are derived from empirical work presented by Meixner (2020). Based on a confirmatory factor analysis, this work proposed a two-factor commitment mode consisting of emotional and behavioral factors. Reliability scores for both factors are presented and of appropriate nature for ongoing empirical work. Criterion validity has not been reported so far on those scales; however, the items from the scales were - as Meixner (2020) explains - derived from other, well evaluated and validated scales, which is taken as an indicator for their criterion validity. However, the present study seeks also to provide appropriate information on this validity. Reliability measures were already provided by Meixner (2020), with Cronbach's Alpha of both scales $\left(\alpha_{\text {emotional }}=93\right.$ and $\alpha_{\text {behavioral }}=.88$ ) being within the optimal range. The measure consists of two distinct scales that measure emotional and behavioral commitment and use a five-point Likert scale.

Perceived Leadership Communication Quality. The Perceived Leadership Communication Questionnaire (PLCQ; Schneider, Maier, Lovrekovic \& Retzbach, 2015) is used to measure leadership communication perceived by the participants. The questionnaire is a concise, reliable, and valid instrument for the survey of leadership communication from the two perspectives of a leader who leads simultaneously, making it well suited for the present study. The authors were able to show a satisfactory criterion validity by finding a correlation of $\mathrm{r}=$ .31 in their validation study with the job satisfaction of the people they interviewed, which supplements the positive findings. The internal consistency of the six-item scale reached an acceptable Cronbach's $\alpha$ of .79. In addition to factor analysis, item homogeneity indices (mean inter-item correlations) were between .33 and .42 (test homogeneity was .39)" (Schneider et al., 
2015, p. 180). The six items of the PLCQ apply a five-point Likert scale to assess the quality of leadership communication. Participants were asked to describe their immediate leader based on these items.

Multifactor Leadership Questionnaire. To assess the perceived leadership approach, participants were asked to evaluate their leader using the 45 items of the multifactor leadership questionnaire (MLQ, Bass \& Avolio, 1995). The questionnaire is based on the distinction between transformational, transactional, and avoidant leadership. A total of nine sub-scales are devised by the MLQ, which are summarized to scales for transformational, transactional, and passive-avoidant leadership. These leadership style descriptions are complemented by three additional subscales (extra effort, effectiveness, and satisfaction) summarized in the leadership scale outcomes. However, more recent research doubted the factorial structure of the sub-scales of the MLQ (Tejeda, Scandura, \& Pillai, 2001). In this study, only the four scales were reported, with the sub-scales only being used to compute the scale values themselves. The MLQ uses a five-point Likert scale. The MLQ is validated both for self-reports and for assessing another person's leadership approach, with the latter being relevant for this paper. Psychometric properties of the MLQ are also reported by Muenjohn and Armstrong (2008), who found overall satisfactory indicators of validity and reliability for the measure originally published by Bass and Avolio (1995).

Big Five Inventory (Short Version). Personality was assessed following the Big Five personality model. The Big Five Inventory (BFI, short version; Rammstedt \& John, 2007) was used. This version was developed on the longer version of the BFI, which consists of 45 items. Based on empirical research and a validation study, the authors formed a ten-item version used in this study. This ten-item version measures the five dimensions of the personality model, using two items per dimension, with one of them being depicted in a negatively structured way, thus requiring re-computation for scale-computing. Rammstedt and John (2005) were able to show that this ten-item version of the Big Five inventory does possess similar psychometric properties as the full version, thus, being an appropriate measure for assessing individuals' personality. However, the downside of this short-measure is that individual facets of the five personality dimensions cannot be assessed; this, however, was outside of the scope of the present research paper anyway. A five-point Likert scale is used by the BFI-short version (Rammstedt \& John, 2005).

\section{Sample}

In this research paper, using a German research panel, a total of $n=300$ participants were presented with measures of organizational commitment, perceived leadership communication quality (PLCQ), perceived leadership style (MLQ), and personality (Big Five). The sample size was chosen following the expected effect sizes and the proposed statistical measures (Burmeister \& Aitken, 2012; Hancock, 2001). The sample itself was acquired utilizing the assistance of a German research panel, which assisted in contacting 300 participants fitting the aimed-for profile: business professionals from various fields in Germany with a minimum of five years working experience. The research focused on the employees' perspectives; thus, all 300 participants were employees, describing their commitment and perception of their leaders' approaches and behaviors. The employees have been, on average, for $M=8.16$ years with their 
current employer. In addition, 32.3\% of them also reported being currently in a leadership position themselves. However, they still reported having direct leaders above them, which they assessed within the current work.

\section{Results}

\section{Descriptive Statistics of the Relevant Variables}

In a first step, descriptive statistics were computed to showcase the variables used within this study regarding their relevant parameters. Table 1 shows the means, standard deviations, and minimum and maximum values of the scales used within this study. There were - apart from the sociodemographic measures - no single items being used for subsequent analyses. Scales were computed following the directions given by the respective papers or manuals in which the measures have been initially published. Regarding the MLQ, the summarized characteristics were used for the subsequent analyses. This implies a total of three scales for leadership (transformational, transactional, passive avoidant) and an additional scale for outcomes of leadership.

As presented in Table 1, there is no missing data for either of the variables. The variables emotional factor and behavioral factor represent the two types of organizational commitment. These two variables were considered for the subsequent analyses, as the research question aims to understand how organizational commitment can be predicted by employee personality (represented by the five Big Five variables), perceived leadership style (transformational leadership, transactional leadership, passive-avoidant leadership), and perceived leadership communication quality.

Table 1

Descriptive Statistics of Relevant Variables

\begin{tabular}{|c|c|c|c|c|c|}
\hline & $\mathrm{N}$ & Minimum & Maximum & $M$ & $S D$ \\
\hline Transformational_Leadership & 300 & 1.00 & 5.00 & 3.23 & .73 \\
\hline Transactional_Leadership & 300 & 1.50 & 5.00 & 3.13 & .56 \\
\hline Overall_Outcomes & 300 & 1.00 & 5.00 & 3.20 & .86 \\
\hline PLCQ & 300 & 1.00 & 5.00 & 3.36 & .93 \\
\hline BFI_E & 300 & 1.00 & 5.00 & 3.37 & .86 \\
\hline BFI_C & 300 & 1.50 & 5.00 & 3.73 & .77 \\
\hline BFI_N & 300 & 1.00 & 5.00 & 2.45 & .92 \\
\hline BFI_O & 300 & 1.00 & 5.00 & 3.46 & .73 \\
\hline emotional_factor & 300 & 1.37 & 5.00 & 3.39 & .68 \\
\hline behavioral_factor & 300 & 1.08 & 4.54 & 3.22 & .62 \\
\hline
\end{tabular}

Table 2 shows that both types of organizational commitment, behavioral and emotional aspects, are positively correlated to the perception of transformational $(r=.53, p<.01 ; r=.50$, $p<.01)$ and transactional leadership $(r=.34, p<.01 ; r=.34, p<.01)$, leadership outcomes $(r$ $=.52 p<.01 ; r=.51, p<.01)$, and perceived leadership communication quality $(r=.53, p<$ $.01 ; r=.51, p<.01)$. However, a negative correlation could be observed between passiveavoidant leadership approaches and organizational commitment $(r=-.26, p<.01, r=-.28, p<$ $.01)$. 
Table 2

Correlations between Leadership and Commitment (own data)

\begin{tabular}{|c|c|c|c|}
\hline & & emotional_factor & behavioral_factor \\
\hline \multirow{3}{*}{ Transformational_Leadership } & Pearson Correlation & $.53^{* *}$ & $.50^{* *}$ \\
\hline & Sig. (2-tailed) & .00 & .00 \\
\hline & $\mathrm{N}$ & 30 & 300 \\
\hline \multirow{3}{*}{ Transactional_Leadership } & Pearson Correlation & $.34^{* *}$ & $.34^{* *}$ \\
\hline & Sig. (2-tailed) & .00 & .00 \\
\hline & $\mathrm{N}$ & 300 & 300 \\
\hline \multirow{3}{*}{ Passive_Avoidant } & Pearson Correlation & $-.26^{* *}$ & $-.28^{* *}$ \\
\hline & Sig. (2-tailed) & .00 & .00 \\
\hline & $\mathrm{N}$ & 300 & 300 \\
\hline \multirow{3}{*}{ Overall_Outcomes } & Pearson Correlation & $.52^{* *}$ & $.51^{* *}$ \\
\hline & Sig. (2-tailed) & .00 & .00 \\
\hline & $\mathrm{N}$ & 300 & 300 \\
\hline \multirow{3}{*}{ PLCQ } & Pearson Correlation & $.53^{* *}$ & $.51^{* *}$ \\
\hline & Sig. (2-tailed) & .00 & .00 \\
\hline & $\mathrm{N}$ & 300 & 300 \\
\hline
\end{tabular}

Note. **Correlation is significant at the 0.01 level (2-tailed).

In the next step, bivariate correlations between the big five variables and the other potential predictors of commitment were computed (Table 3). This analysis showed that an employee's personality is connected to how the employee perceives his leader. However, openness and agreeableness do not seem to be correlated to the perception of the leadership style or the leadership communication, despite the initial assumption that agreeableness might be an influential variable in these regards. However, significant relationships could be shown between the other three big five factors and the indicators of perceived leadership. While for neuroticism only negative correlations could be observed (indicating that a high level of neuroticism goes along with a less positive perception of leadership style and leadership communication), for conscientiousness and extraversion positive correlations could be observed, thus high levels in these two personality factors go along with a tendency to describe leaders as more transformational, to have better leadership communication quality and also as more positive in general (overall outcomes). Also, those scoring higher on conscientiousness, tend to describe their leaders as less passive-avoidant.

Table 3

Correlations between Personality and other Predictors (own data)

\begin{tabular}{|c|c|c|c|c|c|c|}
\hline & & $\begin{array}{c}\text { Transformational_ } \\
\text { Leadership }\end{array}$ & $\begin{array}{l}\text { Transactional_ } \\
\text { Leadership }\end{array}$ & $\begin{array}{l}\text { Passive_ } \\
\text { Avoidant }\end{array}$ & $\begin{array}{c}\text { Overall_ } \\
\text { Outcomes }\end{array}$ & PLCQ \\
\hline \multirow{3}{*}{ BFI_E } & Pearson Correlation & $.17^{* *}$ & .11 & -.10 & $.14^{* *}$ & $.19^{* *}$ \\
\hline & Sig. (2-tailed) & .00 & .05 & .07 & .01 & .00 \\
\hline & $\mathrm{N}$ & 300 & 300 & 300 & 300 & 300 \\
\hline \multirow{3}{*}{ BFI_A } & Pearson Correlation & .05 & -.00 & -.10 & .04 & .04 \\
\hline & Sig. (2-tailed) & .32 & .90 & .06 & .46 & .41 \\
\hline & $\mathrm{N}$ & 300 & 300 & 300 & 300 & 300 \\
\hline \multirow{3}{*}{ BFI_C } & Pearson Correlation & $.13^{*}$ & $.11^{*}$ & $-.15^{* *}$ & $.17^{* *}$ & $.16^{* *}$ \\
\hline & Sig. (2-tailed) & .02 & .04 & .00 & .00 & .00 \\
\hline & $\mathrm{N}$ & 300 & 300 & 300 & 300 & 300 \\
\hline \multirow{3}{*}{ BFI_N } & Pearson Correlation & $-.17^{* *}$ & $-.12^{*}$ & .06 & $-.18^{* *}$ & $-.18^{* *}$ \\
\hline & Sig. (2-tailed) & .00 & .02 & .28 & .00 & .00 \\
\hline & $\mathrm{N}$ & 300 & 300 & 300 & 300 & 300 \\
\hline \multirow{3}{*}{ BFI_O } & Pearson Correlation & -.03 & -.04 & -.09 & -.05 & .06 \\
\hline & Sig. (2-tailed) & .56 & .42 & .12 & .36 & .26 \\
\hline & $\mathrm{N}$ & 300 & 300 & 300 & 300 & 300 \\
\hline
\end{tabular}

Note. $* *$ Correlation is significant at the 0.01 level (2-tailed).

*Correlation is significant at the 0.05 level (2-tailed). 
In a similar vein, the correlations between personality and organizational commitment were computed (Table 4). Again, openness does not seem to play a relevant role in regards to organizational commitment, similarly to how it did not seem relevant in regards to the leadership variables reported in Table 3. However, for the other variables, distinctive correlations could be observed: While the behavioral commitment seems to only be correlated with the personality trait conscientiousness $(r=.233, p<.01)$, the emotional commitment is correlated with all big five traits apart from openness (see Table 4).

Table 4

Correlation between Personality and Commitment (own data)

\begin{tabular}{llcc}
\hline & & emotional_factor & behavioral_factor \\
\hline \multirow{2}{*}{ BFI_E } & Pearson Correlation & $.19^{* *}$ & .06 \\
& Sig. (2-tailed) & .00 & .24 \\
& $\mathrm{~N}$ & 300 & 300 \\
\multirow{2}{*}{ BFI_A } & Pearson Correlation & $.18^{* *}$ & .10 \\
& Sig. (2-tailed) & .00 & .08 \\
& $\mathrm{~N}$ & 300 & 300 \\
\multirow{3}{*}{ BFI_C } & Pearson Correlation & $.28^{* *}$ & $.23^{* *}$ \\
& Sig. (2-tailed) & .00 & .00 \\
& $\mathrm{~N}$ & 300 & 300 \\
BFI_N & Pearson Correlation & $-.24^{* *}$ & -.10 \\
& Sig. (2-tailed) & .00 & .06 \\
& $\mathrm{~N}$ & 300 & 300 \\
\multirow{2}{*}{ BFI_O } & Pearson Correlation & .10 & .06 \\
& Sig. (2-tailed) & .08 & .25 \\
& $\mathrm{~N}$ & 300 & 300 \\
\hline
\end{tabular}

Note. ${ }^{* *}$ Correlation is significant at the 0.01 level (2-tailed).

\section{Regression Analysis}

As the descriptive analysis and the depiction of the results of the bivariate correlations imply, emotional and behavioral aspects of commitment are distinctive variables with (partially) unique correlates - as presented in Table 3 and 4. For the subsequent analyses regarding how both aspects of organizational commitment can be predicted by employee personality, employees' perception of leadership communication quality, and leadership style, both indicators of commitment were considered. Thus, two separate multiple regression analyses were conducted, following the same pattern of a stepwise regression with two blocks. In the first block of each regression, the set of big five variables was proposed as possible predictors to be entered stepwise based on the significance of their variance explanation. The second block of proposed predictors were the variables derived from the MLQ (leadership styles and leadership outcomes) and the perceived leadership communication quality. Again, the variables in this block were entered stepwise into the final equations, based on the significance of their variance explanation. Tables 5 and 6 show the results of the regression analyses, respectively, for the two criterion variables, emotional and behavioral commitment.

As shown in Table 5 and 6, the results of both analyses show comparable, although distinctive, results. Conscientiousness, transformational leadership (perceived), and leadership communication quality (perceived) are relevant predictors for both criteria, although with different impacts. Also, neuroticism proved to be a relevant predictor only for emotional commitment, while it seems irrelevant for behavioral commitment. With an $R^{2}=31$ for behavioral commitment and $R^{2}=.36$ for emotional commitment for both aspects of commitment, meaningful predictions can be made by the set of variables chosen within the study. Out of the set of personality factors, only conscientiousness proved to be a relevant factor 
for both aspects of commitment. Out of the leadership aspects, only transformational leadership (perceived) and perceived leadership communication quality seem relevant on this level. Thus, the perception of transactional leadership and passive-avoidant leadership do not explain variance in commitment, although they were bivariate correlates of both aspects of commitment.

Table 5

Regression analysis - Behavioral Commitment

Model Summary

\begin{tabular}{|c|c|c|c|c|c|c|c|c|c|}
\hline \multirow[b]{2}{*}{ Model } & \multirow{2}{*}{$\mathrm{R}$} & \multirow{2}{*}{$\mathrm{R}^{2}$} & \multirow{2}{*}{ Adjusted $\mathrm{R}^{2}$} & \multirow{2}{*}{$\begin{array}{l}\text { Std. Error of the } \\
\text { Estimate }\end{array}$} & \multicolumn{5}{|c|}{ Change Statistics } \\
\hline & & & & & $\mathrm{R}^{2}$ Change & F Change & df1 & df 2 & Sig. F Change \\
\hline$\overline{1}$ & $.23^{\mathrm{a}}$ & .05 & .05 & .60 & .05 & 17.03 & 1 & 298 & .00 \\
\hline 2 & $.53^{\mathrm{b}}$ & .28 & .28 & .52 & .23 & 97.76 & 1 & 297 & .00 \\
\hline 3 & $.56^{\mathrm{c}}$ & .31 & .31 & .51 & .03 & 13.28 & 1 & 296 & .00 \\
\hline
\end{tabular}

a. Predictors: (Constant), BFI_C

b. Predictors: (Constant), BFI_C, PLCQ

c. Predictors: (Constant), BFI_C, PLCQ, Transformational_Leadership

Table 6

Regression analysis - Emotional Commitment

Model Summary

\begin{tabular}{|c|c|c|c|c|c|c|c|c|c|}
\hline \multirow[b]{2}{*}{ Model } & \multirow{2}{*}{$\mathrm{R}$} & \multirow{2}{*}{$\mathrm{R}^{2}$} & \multirow{2}{*}{ Adjusted $\mathrm{R}^{2}$} & \multirow{2}{*}{$\begin{array}{l}\text { Std. Error of the } \\
\text { Estimate }\end{array}$} & \multicolumn{5}{|c|}{ Change Statistics } \\
\hline & & & & & $\mathrm{R}^{2}$ Change & F Change & df1 & df2 & Sig. F Change \\
\hline 1 & $.286^{\mathrm{a}}$ & .082 & .079 & .65922 & .082 & 26.619 & 1 & 298 & .000 \\
\hline 2 & $.338^{\mathrm{b}}$ & .114 & .108 & .64873 & .032 & 10.718 & 1 & 297 & .001 \\
\hline 3 & $.584^{\mathrm{c}}$ & .341 & .334 & .56047 & .227 & 101.902 & 1 & 296 & .000 \\
\hline 4 & $.608^{\mathrm{d}}$ & .370 & .362 & .54886 & .029 & 13.659 & 1 & 295 & .000 \\
\hline
\end{tabular}

a. Predictors: (Constant), BFI_C

b. Predictors: (Constant), BFI_C, BFI_N

c. Predictors: (Constant), BFI_C, BFI_N, Transformational_Leadership

c. Predictors: (Constant), BFI_C, BFI_N, Transformational_Leadership

d. Predictors: (Constant), BFI_C, BFI_N, Transformational_Leadership, PLCQ

\section{Discussion}

The present study sought to foster understanding, how employees' personalities and their perception of their leaders' behavior influences two aspects of organizational commitment, as defined by Meixner (2020). A literature review revealed that employees' personality, leadership styles, and leadership behavior could influence organizational commitment. Especially the role of transformational leadership was pointed out here: As Bass (1999) and Carter et al. (2013) showcase, one of the main goals of transformational leadership is to positively influence the relationship between a company (and its leaders) on the one side and its employees on the other side. This is typically achieved through an employee-oriented leadership approach that aims to put the company's goals in the center of attention and make a connection between those and employees' motivations and goals. Leadership communication plays a vital role in this leadership approach, as forming a positive relationship between leaders and employees becomes a core goal. Especially the emotional aspects of organizational commitment seem to be influenced by this approach (Yang et al., 2011). However, this does not rule out the relevance of transactional leadership, which, as shown by authors such as Dai et al. (2013), can also be beneficial in dependence on its use-case. However, transactional leadership seems to focus less on strengthening organizational commitment and rather induces a transaction-based 
relationship between leaders and employees. However, as Bass and Avolio (1995) point out, both leadership styles are not mutually exclusive.

These findings in regards to transformational and transactional leadership lead to the findings of the empirical study conducted within this paper. Here, the focus was shifted towards perceived leadership behavior and approaches - as the study centered on employees' perspectives and perceptions. Thus, it was not assessed whether their leaders behaved in a transformational, transactional or passive-avoidant way, but rather how employees perceived this behavior. This was done using the MLQ that is considered to be a reliable and valid measure both for self-ratings and for other-ratings (Bass \& Aviolo, 1995; Tejeda et al. 2001).

Using this empirical approach as described already, the research question can be answered directly: Employee personality plays a vital role in predicting organizational commitment. This was shown both on a bivariate, correlation-based level, where especially for emotional commitment, strong relationships towards multiple personality factors could be established. Based on the multiple regression analysis conducted stepwise in two blocks, the role of conscientiousness stands out as relevant - for both emotional and behavioral commitment. Conscientiousness is an important predictor that - on the personality side - gets supplemented by neuroticism for emotional commitment. However, the findings show that the perception of leadership and leadership communication also aid in predicting organizational commitment.

These findings point out that only the perception of transformational behavior seems relevant for predicting organizational commitment; whereas neither transactional nor passive-avoidant behavior plays a significant role from this perspective. However, pointing back towards the bivariate analyses, especially passive-avoidant leadership behavior negatively relates to commitment. However, due to inter-correlations between the (perceived) leadership types, only the transformational approach seems to be a significant predictor of commitment, along with the perceived quality of leadership communication.

To sum up, it can be stated that conscientiousness (and in the case of emotional commitment, neuroticism), transformational leadership, and leadership communication quality are relevant predictors of organizational commitment, explaining around one-third of variance. These results, furthermore, can be considered an indicator of criterion validity for the measure of emotional and behavioral commitment as proposed by Meixner (2020). Furthermore, the correlations with various leadership and personality variables align with the initial assumptions of this paper and the one presented by Meixner (2020). Thus, the measure used here seems to possess adequate criterion validity. The correlations found are high enough to show the predictive validity but small enough to clarify that it measures a construct distinct from the perception of leadership behavior.

\section{Limitations of the Study}

One of the core limitations of the current study lies in the nature of correlational analyses itself: The correlations computed between personality, for example, show that extraversion and conscientiousness - among others - go along with higher ratings in regards to perceived leadership quality and a stronger tendency to describe leaders as transformational and partially transactional. However, these findings do not necessarily imply that leaders of extraverted and conscientious employees are more transformational or more efficient and satisfactory, as one possible explanation of these findings might imply. Also, it cannot be proven that those scoring 
higher on these personality variables tend to judge their leaders more positively, independent of their actual leadership quality. Thus, while the findings point towards the relationship between personality and leadership perception, no conclusive decisions can be made based on these results. However, an educated guess led by the relevant literature on the topic might imply that the relationship is complex. Given the strong focus on communication found in transformational leadership (Men, 2014) and which is also part of the leadership communication quality, it seems safe to assume that leaders following such an approach would choose employees who tend to be more extroverted. Also, extraverted employees might value leaders with a strong focus on communication and the transformational nature of leadership higher than introverted employees do. Indications for both of these interpretations exist, and they also do not seem mutually exclusive.

In general, the interpretability of the study is limited therein, that only the perception of leadership was analyzed. The research aimed to foster an understanding of how personality and the perceived leadership style influence the two aspects of organizational commitment. While the present study clearly showed how these factors are connected to each other, it leaves the research gap for follow-up studies to reveal how actual leadership can play an influencing role in this model. However, the assessment of actual leadership in comparison to organizational commitment would require a drastically more complex design, as it can - for an economic reason - only very rarely be found. It would be necessary to not only gather data from employees (as done within this study) or only from leaders but also from both, leading to a paired sample, in which the data of individual employees could be linked to data from their respective leaders or line managers.

The findings regarding neuroticism, which is a significant predictor of emotional commitment, do not seem to come as a surprise, as the scientific literature on the big five-factor neuroticism (thus, sub-clinical neuroticism) reveals. Moreover, highly neurotic persons are generally described as more sensitive regarding emotional stressors (Boyes \& French, 2010). Thus the result that neuroticism is connected to emotional commitment seems like a logical conclusion.

\section{Conclusion, Contribution, and Outlook}

Concludingly, the present work showed that both employees' personalities and leadership behavior are relevant for the formation of organizational commitment. Organizational commitment, thus, is dependent both on internal and external sources, as - among others already assumed by Meixner (2020). Therefore, this paper builds on and expands the existing literature on organizational commitment, contributing to the current state of research. While it seemed clear that there is a link between leadership behavior and commitment, the present study was able to quantify this relationship using standardized measures. Previously conducted studies typically focused on the personality or leadership perspective, respectively, whereas the present paper aimed to combine those two approaches within one methodological approach.

Also, it was able to empirically showcase the validity of the model of organizational commitment presented by Meixner (2020). Therein the relevance of emotional and behavioral commitment and their linkage to leadership behavior was shown exploratory, with the present study adding evidence to the proposed relationship. The usage of pre-evaluated measurements such as the Multifactor Leadership Questionnaire (Bass \& Avolio, 1995) or the Big Five 
Inventory (Rammstedt \& John, 2007) provides a high level of reliability, validity, and objectivity to the study, thus allowing for a straightforward interpretation of the data found with only minor concerns of their psychometric quality. This seems to be a major contribution to the existing state of research, as psychometric quality within leadership research tends to be underreported (Scherbaum, Finlinson, Barden, \& Tamanini, 2006).

However, more elaborate studies will be necessary to foster an understanding of the relationship between these internal and external sources of organizational commitment. As the literature review conducted within this paper shows, most studies focus either on the employee perspective (as done within this study) or on the leader perspective. To fully understand how actual leadership behavior influences employees' commitment, a research design connecting employees and leaders in one dataset would be necessary. However, it seems clear that the combination of such data in a dataset of a meaningful size that allows for statistical analyses seems like a major obstacle. Also, the role of the companies themselves needs to be taken into account: Such studies will have to either limit themselves to one company (to eliminate variance in regards to general corporate culture and similar variables) or use such a wide array of companies that those company-based variables get averaged out of relevance.

The introductory statements of this research paper explained that employees are (still and more than ever) one of the most important resources of contemporary companies and businesses. Fostering their commitment, thus, becomes one of the main goals of business leaders. The present study was able to show that, and this also seems true in practice: Leaders who use a transformational approach and who can communicate in a way that is perceived as clear, concise, and positive by their employees can improve organizational commitment and thereby lead to better engagement, strengthened motivation, and better performance. In these regards, it seems important to mention an observation of Busse (2014a, p. 61): "transformational leadership is trainable i.e. leaders can learn and practice to become transformational leaders or to improve their ability to lead transformational".

While this paper addressed the linkage between this leadership behavior - or the perception of the behavior - future research will focus strongly on the mediating role that various personality variables take on. Nevertheless, the present work can already be seen as a first step towards understanding the complex relationship between external and internal factors influencing commitment (with leadership behavior being the external and personality one of the internal factors). Subsequent work focuses on personal values and their relevance to how various leadership behaviors are translated into commitment.

\section{References}

Adams, A. (2007). Developing leadership wisdom. International Journal of Leadership in Public Services, 3(2), 39-50.

Allen, N. J., \& Meyer, J. P. (1990). The measurement and antecedents of affective, continuance and normative commitment to the organization. Journal of Occupational Psychology, 63(1), 1-18.

Athar, H. S. (2020). The Influence of Organizational Culture on Organizational Commitment Post Pandemic Covid-19. International Journal of Multicultural and Multireligious Understanding, 7(5), 148-157.

Avolio, B. J., Bass, B. M., \& Jung, D. I. (1999). Re-examining the components of transformational and transactional leadership using the Multifactor Leadership. Journal of Occupational and Organizational Psychology, 72(4), 441-462. 
Avolio, B. J., Zhu, W., Koh, W., \& Bhatia, P. (2004). Transformational leadership and organizational commitment: Mediating role of psychological empowerment and moderating role of structural distance. Journal of Organizational Behavior: The International Journal of Industrial, Occupational and Organizational Psychology and Behavior, 25(8), 951-968.

Balsmeier, B., \& Woerter, M. (2019). Is this time different? How digitalization influences job creation and destruction. Research Policy, 48(8), 103765.

Barrick, M. R., \& Mount, M. K. (1991). The big five personality dimensions and job performance: a meta-analysis. Personnel Psychology, 44(1), 1-26.

Bass, B. M. (1997). Does the transactional-transformational leadership paradigm transcend organizational and national boundaries? American Psychologist, 52(2), 130-139.

Bass, B. M. (1999). Two decades of research and development in transformational leadership. European Journal of Work and Organizational Psychology, 8(1), 9-32.

Bass, B. M., \& Avolio, B. J. (Eds.). (1994). Improving organizational effectiveness through transformational leadership. Thousand Oaks: Sage.

Bass, B., \& Avolio, B. (1995). MLQ multifactor leadership questionnaire. Menlo Park: Mind Garden.

Bass, B. M., \& Riggio, R. E. (2006). Transformational leadership. Hove, UK: Psychology press.

Bedell, K., Hunter, S., Angie, A., \& Vert, A. (2006). A historiometric examination of Machiavellianism and a new taxonomy of leadership. Journal of Leadership and Organizational Studies, 12(4), 50-72.

Berberoglu, A. (2018). Impact of organizational climate on organizational commitment and perceived organizational performance: empirical evidence from public hospitals. BMC Health Services Research, 18(1), 1-9.

Bono, J. E., \& Judge, T. A. (2004). Personality and transformational and transactional leadership: a meta-analysis. Journal of Applied Psychology, 89(5), 901-912.

Boyes, M. E., \& French, D. J. (2010). Neuroticism, stress, and coping in the context of an anagram-solving task. Personality and Individual Differences, 49(5), 380-385.

Burmeister, E., \& Aitken, L. M. (2012). Sample size: How many is enough?. Australian Critical Care, 25(4), 271-274.

Busse, R. (2014a). Comprehensive leadership review-literature, theories and research. Advances in Management, 7(5), 5266.

Busse, R. (2014b). Corporate culture, organizational change and meaning at work-linking human resources with business ethics. Human Systems Management, 33(1-2), 47-50.

Carter, M. Z., Armenakis, A. A., Feild, H. S., \& Mossholder, K. W. (2013). Transformational leadership, relationship quality, and employee performance during continuous incremental organizational change. Journal of Organizational Behavior, 34(7), 942-958.

Chambers, E. G., Foulon, M., Handfield-Jones, H., Hankin, S. M., \& Michaels, E. G. (1998). The war for talent. McKinsey Quarterly, 3, 44-57.

Cobb-Clark, D. A., \& Schurer, S. (2012). The stability of big-five personality traits. Economics Letters, 115(1), 11-15.

Cohen, A. (2017). Organizational Commitment and Turnover: A Meta-Analysis. Academy of management journal, 36(5), $1140-1157$

Dai, Y. D., Dai, Y. Y., Chen, K. Y., \& Wu, H. C. (2013). Transformational vs transactional leadership: which is better? International Journal of Contemporary Hospitality Management, 25(5), 760-778.

Elangovan, A. R. (2001). Causal ordering of stress, satisfaction and commitment, and intention to quit: a structural equations analysis. Leadership and Organization Development Journal, 22(4), 159-165.

Erdheim, J., Wang, M., \& Zickar, M. J. (2006). Linking the Big Five personality constructs to organizational commitment. Personality and Individual Differences, 41(5), 959-970.

Firth, L., Mellor, D. J., Moore, K. A., \& Loquet, C. (2004). How can managers reduce employee intention to quit? Journal of Managerial Psychology, 19(2), 170-187.

Frooman, J., Mendelson, M. B., \& Murphy, J. K. (2012). Transformational and passive avoidant leadership as determinants of absenteeism. Leadership and Organization Development Journal, 33(5), 447-463.

Geyer-Klingeberg, J., Nakladal, J., Baldauf, F., \& Veit, F. (2018, July). Process Mining and Robotic Process Automation: A Perfect Match. In BPM (Dissertation/Demos/Industry) (pp. 124-131).

Goldberg, L. R. (1990). An alternative "description of personality": the big-five factor structure. Journal of Personality and Social Psychology, 59(6), 1216-1229.

Hancock, G. R. (2001). Effect size, power, and sample size determination for structured means modeling and MIMIC approaches to between-groups hypothesis testing of means on a single latent construct. Psychometrika, 66(3), 373-388. 
Hetland, H., Sandal, G. M., \& Johnsen, T. B. (2008). Followers' personality and leadership. Journal of Leadership and Organizational Studies, 14(4), 322-331.

Horwitz, I. B., Horwitz, S. K., Daram, P., Brandt, M. L., Brunicardi, F. C., \& Awad, S. S. (2008). Transformational, transactional, and passive-avoidant leadership characteristics of a surgical resident cohort: analysis using the multifactor leadership questionnaire and implications for improving surgical education curriculums. Journal of Surgical Research, 148(1), 49-59.

Hurtz, G. M., \& Donovan, J. J. (2000). Personality and job performance: The Big Five revisited. Journal of Applied Psychology, 85(6), 869-879.

Jackson, T. A., Meyer, J. P., \& Wang, X. H. (2013). Leadership, commitment, and culture: A meta-analysis. Journal of Leadership and Organizational Studies, 20(1), 84-106.

Jogulu, U. D. (2010). Culturally-linked leadership styles. Leadership and Organization Development Journal, 31(8), 705719.

Judge, T. A., Higgins, C. A., Thoresen, C. J., \& Barrick, M. R. (1999). The big five personality traits, general mental ability, and career success across the life span. Personnel Psychology, 52(3), 621-652.

Klassen, R. M., \& Chiu, M. M. (2011). The occupational commitment and intention to quit of practicing and pre-service teachers: Influence of self-efficacy, job stress, and teaching context. Contemporary Educational Psychology, 36(2), 114129.

Kurzweil, R. (2000). The age of spiritual machines: When computers exceed human intelligence. Munich: Penguin.

Landay, K., Harms, P. D., \& Credé, M. (2019). Shall we serve the dark lords? A meta-analytic review of psychopathy and leadership. Journal of Applied Psychology, 104(1), 183.

Larson, D., \& Chang, V. (2016). A review and future direction of agile, business intelligence, analytics and data science. International Journal of Information Management, 36(5), 700-710.

MacKenzie, S. B., Podsakoff, P. M., \& Rich, G. A. (2001). Transformational and transactional leadership and salesperson performance. Journal of the academy of Marketing Science, 29(2), 115-134.

Mahmoud, A. (2008). A study of nurses' job satisfaction: the relationship to organizational commitment, perceived organizational support, transactional leadership, transformational leadership, and level of education. European Journal of Scientific Research, 22(2), 286-295.

Mathieu, C., Neumann, C. S., Hare, R. D., \& Babiak, P. (2014). A dark side of leadership: Corporate psychopathy and its influence on employee well-being and job satisfaction. Personality and Individual Differences, 59, 83-88.

Meixner, T. (2020). Organizational Commitment - Re-structuring a concept crucial for management and leadership using a confirmatory factor analysis. International Journal of Organizational Leadership, 9(2), 77-92.

Men, L. R. (2014). Why leadership matters to internal communication: Linking transformational leadership, symmetrical communication, and employee outcomes. Journal of Public Relations Research, 26(3), 256-279.

Meyer, J. P., \& Allen, N. J. (1991). A three-component conceptualization of organizational commitment. Human Resource Management Review, 1(1), 61-89.

Morgan, J. (2017). The employee experience advantage: How to win the war for talent by giving employees the workspaces they want, the tools they need, and a culture they can celebrate. Hoboken: John Wiley \& Sons.

Morrison, K. A. (1997). How franchise job satisfaction and personality affects performance, organizational commitment, franchisor relations, and intention to remain. Journal of Small Business Management, 35(3), 39-67.

Muenjohn, N., \& Armstrong, A. (2008). Evaluating the structural validity of the multifactor leadership questionnaire (MLQ), capturing the leadership factors of transformational-transactional leadership. Contemporary Management Research, 4(1).

Neubauer, A. C., Bergner, S., \& Felfe, J. (2012). Leadership Judgement Indicator (LJI). Deutschsprachige Adaptation des Leadership Judgement Indicator (LJI) von M. Lock und R. Wheeler, Bern: Verlag Hans Huber.

Poropat, A. E. (2009). A meta-analysis of the five-factor model of personality and academic performance. Psychological Bulletin, 135(2), 322-338.

Pretsch, J. (2019). Digitalisierung und ihre strategische Implementation unter Berücksichtigung des Faktors, Mensch [Digitalization and ist strategic implementation under consideration of the human factor]. In. S. Bergner, J. Fleiß \& A. Gutschelhofer (Hrsg.), Wandel gestalten. Beiträge der Managementforschung zu Herausforderungen der Unternehmensführung. [Shaping Change - Contributions of Management Research to Leadership Challenges.], p. 97-130 Graz: Leykam.

Rammstedt, B., \& John, O. P. (2005). Kurzversion des big five inventory (BFI-K). [Short version of the Big Five Inventory (BFI-K)] Diagnostica, 51(4), 195-206.

Rammstedt, B., \& John, O. P. (2007). Measuring personality in one minute or less: A 10-item short version of the Big Five Inventory in English and German. Journal of Research in Personality, 41(1), 203-212. 
Roberts, B. W. (2006). Personality development and organizational behavior. Research in Organizational Behavior, 27, 140.

Roberts, B. W., Jackson, J. J., Fayard, J. V., Edmonds, G., \& Meints, J. (2009). Conscientiousness. In M. R. Leary \& R. H. Hoyle (Eds.), Handbook of individual differences in social behavior (pp. 369-381). The Guilford Press.

Scherbaum, C. A., Finlinson, S., Barden, K., \& Tamanini, K. (2006). Applications of item response theory to measurement issues in leadership research. The Leadership Quarterly, 17(4), 366-386.

Schilling, J. (2009). From ineffectiveness to destruction: A qualitative study on the meaning of negative leadership. Leadership, 5(1), 102-128.

Schilling, J., \& Schyns, B. (2014). The causes and consequences of bad leadership [Editorial]. Zeitschrift für Psychologie, 222(4), 187-189.

Schneider, F. M., Maier, M., Lovrekovic, S., \& Retzbach, A. (2015). The perceived leadership communication questionnaire (PLCQ): Development and validation. The Journal of Psychology, 149(2), 175-192.

Steers, R. M. (1977). Antecedents and outcomes of organizational commitment. Administrative Science Quarterly, 22(1), 4656.

Suseno, Y., \& Pinnington, A. H. (2017). The war for talent: Human capital challenges for professional service firms. Asia Pacific Business Review, 23(2), 205-229.

Taylor, R. H., Menciassi, A., Fichtinger, G., Fiorini, P., \& Dario, P. (2016). Medical robotics and computer-integrated surgery. In B. Siciliano, \& O. Khatib (Eds): Springer handbook of robotics (pp. 1657-1684). Cham: Springer.

Tejeda, M. J., Scandura, T. A., \& Pillai, R. (2001). The MLQ revisited: Psychometric properties and recommendations. The Leadership Quarterly, 12(1), 31-52.

Ulrich, D. (2015). From war for talent to victory through organization. Strategic HR Review, 14(1/2), 8-12..

Ulrich, D., \& Smallwood, N. (2012). What is talent?. Leader to Leader, 2012(63), 55-61.

Weiss, H. M., \& Adler, S. (1984). Personality and organizational behavior. Research in Organizational Behavior, 6, 1-50.

Wolf, G. (2014). Mitarbeiter anziehen, motivieren, binden: Emotionen entscheiden. Service Today, 3, 14-17.

Yahaya, R., \& Ebrahim, F. (2016). Leadership styles and organizational commitment: literature review. Journal of Management Development, 35(2), 190-216.

Yang, F. H., Wu, M., Chang, C. C., \& Chien, Y. (2011). Elucidating the relationships among transformational leadership, job satisfaction, commitment foci and commitment bases in the public sector. Public Personnel Management, 40(3), $265-278$.

Yousef, D. A. (2017). Organizational commitment, job satisfaction and attitudes toward organizational change: A study in the local government. International Journal of Public Administration, 40(1), 77-88.

\section{Acknowledgements}

Not applicable.

\section{Disclosure Statement}

No potential conflict of interest was reported by the authors.

\section{Funding Acknowledgements}

Not applicable.

\section{Open Access}

The International Journal of Organizational Leadership publishes open access articles under the terms of the Creative Commons Attribution (CC BY) License, which permits use, distribution, and reproduction in any medium, provided the original work is properly cited. 